\title{
Beltrão, Jane Felipe; Lacerda, Paula Mendes (Org.). 2017 Amazônias em tempos contemporâneos: entre diversidades e adversidades. 1. Ed. Rio de Janeiro: Mórula editorial/Aba publicações. 284 pp.
}

\author{
THAIS DLAS LUZ BORGES SANTOS
}

Amazônias em tempos contemporâneos: entre diversidades e adversidades inaugura a coleção de livros paradidáticos organizados pela Associação Brasileira de Antropologia (ABA) e pensados em um contexto em que se faz necessário aproximar a produção antropológica brasileira à educação básica. A educação básica é encarada como lugar privilegiado na formação cidadã de todos os brasileiros. Direcionar um conteúdo antropológico a esse público tem como objetivo fundamentar um Brasil plural que respeita a sua diversidade; daí a intencionalidade do título em colocar Amazônias no plural. A ideia é que em todos os capítulos sejam propostas atividades para serem realizadas pelos alunos em sala de aula ou até mesmo na comunidade em que estão inseridos, ainda que esse exercício esteja ausente em três capítulos do livro, a reflexão sobre os desafios dessa pluralidade em tempos contemporâneos está fortemente presente. Nas palavras das organizadoras, Jane Felipe Beltrão e Paula Mendes Lacerda, "espera-se que a diversidade se sobreponha às adversidades do dia a dia na escola e apresente as Amazônias de seus protagonistas" (: 14).

São 15 artigos divididos em seis partes que dialogam entre si, conectando a temática, áreas do conhecimento e pesquisadores indígenas e não indígenas. Os 20 pesquisadores-autores envolvidos nesse projeto problematizam a questão indígena, efetivação de direitos, direitos humanos e narrativas, seja a partir da medicina, do direito, da antropologia, da história, da arqueologia, da educação ou até mesmo a partir do campo da produção de audiovisual.

Na primeira parte, intitulada "Amazônia, História e Diversidade", os capítulos "Alteridade e consciência histórica: a história indígena em seus próprios termos", escrito por Rhuan Carlos dos Santos e Jane Felipe Beltrão, e "Entre histórias locais e narrativas oficiais: proposta para uma abordagem sobre a ocupação amazônica a partir das escolas", da autora Rita de Cássia Melo Santos, apresentam os conceitos de alteridade, consciência histórica e narrativa, para entendermos que a memória histórica, contextualizada, faz parte da noção de identidade acionada pelos diversos sujeitos e que a diferença se faz ao confrontar as várias historicidades presentes no nosso entorno. A história como elemento de reinterpretação identitária que propicia a autoafirmação. Beltrão e Santos validam seu ponto de vista a partir da experiência com o narrador de histórias Miguel Carvalho, indígena Tembé/Tentehara cuja aldeia está localizada na região nordeste do estado do Pará. Melo Santos vai afirmar que o espaço escolar é lugar privilegiado para se con- 
trapor as inúmeras histórias locais às narrativas oficiais de ocupação da Amazônia, cujos regimes políticos adotavam posturas verticais na construção de um plano de ocupação da Região Norte do Brasil, silenciando as vozes ali já presentes.

Já nos capítulos "Comunicação: controle e rebeldia”, escrito por Bruno Pacheco de Oliveira, e "Para o Pará e o Amazonas: Látex. Notas sobre as pressões e violações no interior da Amazônia na economia extrativista", da autora Katiane Silva, os autores seguem com a proposta de refletir sobre a história que (não) é contada acerca da diversidade identitária e de narrativas na Amazônia. Pacheco propõe que o uso das mídias e dos recursos tecnológicos pode promover o protagonismo local e, no caso dos povos cujos direitos são diferenciados, populações originárias e grupos étnicos, promover o conhecimento e divulgação dessa polifonia representada pelo movimento da luta pela terra, respeito ao meio ambiente etc. Silva traz à tona outras narrativas da Belle Époque Amazônica em Belém-PA e Manaus-AM e as mudanças que aconteceram fruto da grande extração do látex na região. Os museus falam do auge da borracha, riqueza e desenvolvimento. Já Silva mostra as violações de direitos e demais violências que o povo local passou antes, durante e depois do auge da borracha.

Na segunda parte, intitulada "Movimentos Sociais e Gênero", nos capítulos “Movimentos Sociais e escolas: possibilidades de ação conjunta e de fortalecimento mútuo", escrito por Paula Mendes Lacerda, "Gênero e sexualidade em sala de aula: um diálogo com estudantes de povos e comunidades tradicionais", escrito por Camille Gouveia Castelo Branco Barata e Mariah Torres Aleixo, e "Povos indígenas e igualdade étnico-racial: horizontes políticos para as escolas", da autora Jane Felipe Beltrão, a intenção é apresentar e compreender os movimentos sociais como defensores de direitos, como elemento de fortalecimento comunitário e também identificar a influência das pautas reivindicatórias dos movimentos no plano político nacional. Lacerda contrapõe os processos de organização do espaço, ocupação territorial, políticas de exploração de recursos naturais e megaprojetos, com o processo de descentralização política, participação comunitária e identidades sociopolíticas, manifestadas em movimentos sociais que pautam decisões democráticas e consolidação de direitos. Barata e Aleixo propõem que cada sujeito opera com identidades múltiplas e que raça, gênero e sexualidades são aspectos cruciais e relacionais no dia a dia de todas as pessoas. Eles operam como marcadores sociais da diferença e é necessário construir uma reflexão do tema em todos os níveis da vida, formais ou informais, para demonstrar e garantir as pluralidades. As autoras construíram o texto baseado na experiência da oficina Gênero e orientação sexual: interfaces da etnicidade com estudantes do curso de Etnodesenvolvimento da Universidade Federal do Pará. Beltrão expõe os desafios políticos para as escolas em uma ação efetiva contra o racismo e em prol da igualdade étnico-racial. A autora inicia falando em responsabilidade, reivindicação e soluções étnicas comparando a experiência com o Plano de Gestão Territorial e Ambiental da terra indígena Kampa [Ashaninka] do Acre e a experiência do primeiro encontro de mulheres indígenas da Amazônia colombiana que reuniu, em Bogotá, quase 30 indígenas de etnias diferentes em 2003. A questão colocada por esses indígenas era a de como o conhecimento indígena "tradicional" conversa, aprende e quer conviver com os "brancos". Segundo Beltrão, o desafio em contextos de multiculturalidades é a garantia da igualdade, garantia de políticas que valorizem a diversidade cultural, as várias formas de se pensar no mundo e, em especial, no campo da educação, um 
projeto político pedagógico que promova direitos e justiça para as pessoas indígenas e sua cultura, longe de uma visão estereotipada e conservadora.

Na terceira parte, "Direitos Diferenciados", os capítulos "Educação em Direitos Humanos na escola: subsídios aos docentes e exercício da cidadania”, do autor Assis da Costa Oliveira, e “Agora, nós é que decidimos': o direito à consulta e consentimento prévio", escrito por Rodrigo Oliveira, refletem sobre como desenvolver práticas alinhadas com os direitos humanos, sobre o direito à consulta e consentimento prévio, livre e informado, o direito à autodeterminação e os desafios encontrados frente a políticas estatais que visam a homogeneizar e a invisibilizar pessoas de direitos diferenciados e situações de violação de direitos. Costa Oliveira afirma que é preciso construir um plano de ação que valorize as identidades de diversos grupos sociais (mulheres, crianças, negros, povos indígenas, grupos LGBT, entre outros), para assim minar as situações de discriminação e desigualdade que esse público é alvo. O texto está direcionado para pessoas que trabalham no âmbito escolar e traz elementos metodológicos para a Educação em Direitos Humanos na escola inspirado na teoria da educação popular freireana e nos documentos jurídicos que trabalham e lutam pelos direitos humanos no plano internacional e nacional. Oliveira apresenta todo o marco jurídico que influencia, no Brasil, a consulta e consentimento prévio, livre e informado dos grupos etnicamente diferenciados. Com uma linguagem simples e concisa o autor demonstra que mais de uma década após a ratificação da Convenção 169 da OIT o Brasil pouco avançou no estabelecimento de uma relação horizontal com seus povos e comunidades e tradicionais, bem como criou mecanismos internos que legalizam a violação de muitos dos direitos desses povos.

Na quarta parte, "Proposta de Trabalho", o capítulo "Artefatos para o ensino: a pesquisa por meio de práticas criativas com a cultura material", escrito por Thiago Lopes da Costa Oliveira, aponta um caminho para pesquisa compartilhada a partir de algumas experiências do autor com o povo indígena Baniwa localizado no noroeste da Amazônia e com o povo Kayapó do sul do Pará. O autor ensina-nos como produzir coleções etnográficas estabelecendo uma relação dialógica com os grupos trabalhados e resgatando toda a carga histórica, afetiva, ritual e educativa dos objetos. Organização do trabalho e transmissão do conhecimento são pontos essenciais nessa compreensão.

Já o capítulo "Sobre povos indígenas e diversidade na escola: superando estereótipos", da autora Rosani de Fátima Fernandes, é um relato profundo e rico sobre os desafios reais que ela, enquanto mulher, indígena, professora e mãe, vem enfrentando no estado Pará. Na visão da autora, o sistema educacional "contribui para continuidade de preconceitos, do racismo, da intolerância com povos culturalmente diferenciados e a necessidade de novas posturas". Muito sensivelmente vamos entendendo os desafios da interculturalidade a partir da trajetória de Fernandes e qual a relação desses desafios com o Estado brasileiro. $\mathrm{O}$ texto é um chamado para a superação de estereótipos e valorização da diversidade.

Na quinta parte, “Campos da Diversidade e do Patrimônio”, os capítulos “A arqueologia conta histórias", da autora Clarisse Callegari Jacques, e "Política indígena e política escolar: interfaces e negociações na implantação da Escola Indígena Pamáali - Alto Rio Negro”, escrito por Laise Lopes Diniz e Luiza Garnelo, apresentam, por um lado, como a arqueologia, enquanto estudiosa do patrimônio, conta histórias de "todos nós", e, por outro lado, as singularidades de um projeto de uma comunidade-escola indígena no 
Alto Rio Negro. Segundo Jacques, os objetos que nos rodeiam contam uma história de quem somos, onde estivemos, com quem relacionamos e o que gostamos. A arqueologia é parceira de vários campos do saber, e a antropologia e a história são um deles, valorizando assim as narrativas em torno do mesmo objeto. O objetivo é entender a arqueologia como ferramenta para compreensão de fatos passados dos artefatos e analisar as diferentes informações, narrativas, que existem sobre ele na atualidade. Já Diniz e Garnelo expõem sobre a Escola Indígena Baniwa/Coripaco Pamáali, criada no ano $2000 \mathrm{em}$ um contexto que se fazia urgente a criação de um sistema escolar autogestionário levando em consideração o conhecimento tradicional indígena. Foram necessários vários esforços dos líderes indígenas para lograr um diálogo com os órgãos municipais e estadual de gestão escolar. O Projeto Político Pedagógico da Pamáali é fruto desse diálogo e incluiu a participação de xamãs e pais Baniwa/Coripaco e ponderou aquilo que é desejado e o que de fato é possível fazer em dadas circunstâncias. Os desafios no estabelecimento de uma escola indígena exigem seriedade em todo o processo e principalmente a criação de uma política em prol da continuidade e manutenção de uma educação diferenciada.

Na última parte, "Povos indígenas e saúde", os capítulos "A experiência de formação de agentes comunitários indígenas de saúde, à luz das políticas públicas de saúde e da promoção da diversidade cultural", das autoras Luiza Garnelo, Sully Sampaio e Ana Lucia Pontes, e "Saúde indígena e diversidade no Brasil Plural", escrito por William César Lopes Domingues, problematizam como lidar com situações sociais e de saúde em áreas multiétnicas. Garnelo, Sampaio e Pontes relatam a experiência com o curso técnico profissionalizante, vinculado ao ensino médio, de agentes comunitários indígenas de saúde no noroeste da Amazônia. O curso técnico usou vários recursos para alinhar a formação com o perfil dos estudantes. A matriz curricular do curso, baseada na educação escolar indígena, optou pelo "bilinguismo, diversidade cultural, interculturalidade, relação dialógica como fundamento do processo pedagógico", bem como se manteve fiel às "orientações técnicas para a formação profissional neste nível". O nível de complexidade e comprometimento com cursos dessa natureza, e todos os enfrentamentos com discursividades divergentes da saúde, é alto, mas possível. Domingues apresenta lógicas indígenas da saúde a partir da sua vivência com seu povo Xacriabá e atualmente com os Asurini do Xingu. Na visão do autor, tratar o Brasil e o sistema de saúde enquanto espaços formados por povos diversos e plurais "não se trata de dizer que os sistemas indígenas são melhores e nem piores do que o sistema ocidental que tem o SUS como modelo de atenção à saúde, trata-se apenas de reconhecer que são diferentes e que os diversos sistemas de saúde dos vários povos indígenas têm lógica e estrutura próprias e cuidaram da saúde destes povos desde tempos imemoriais quando nós não tínhamos acesso à medicina ocidental".

Cabe ressaltar que esse livro também é resultado do projeto "Patrimônio, Diversidade Sociocultural, Direitos Humanos e Políticas Públicas na Amazônia Contemporânea" desenvolvido por meio da parceria entre o Programa de Pós-Graduação em Antropologia da Universidade Federal do Pará (PPGA/ UFPA) e o Programa de Pós-Graduação em Antropologia Social do Museu Nacional (PPGAS/MN). O objetivo desse projeto foi "compreender de forma interdisciplinar as múltiplas estratégias de negociação de identidades que se desenham pelos agentes sociais em face de contextos de mudança acelerada por que passam os cenários urbanos e rurais da Amazônia na contemporaneidade" (:08). Pelo que foi exposto até aqui, é possível perceber que essa compreensão interdisciplinar propiciou ao leitor um panorama teórico 
e geo-histórico da Amazônia a partir do exercício de uma antropologia simétrica, difundida pelo francês Bruno Latour, que sugere, para o texto etnográfico, a articulação dos diversos atores e modos plurais de existência em perspectiva, em rede.

Thais Dias Luz Borges Santos é bacharel em Ciências Socias pela Universidade Estadual de Montes Claros. Mestre em Ciências Sociais - Desenvolvimento, Agricultura e Sociedade pelo CPDA/Universidade Federal Rural do Rio de Janeiro. Doutoranda em Antropologia pelo PPGAS/UFG.

RECEBIDO: $02 / 04 / 2018$

APROVADO: $30 / 01 / 2019$ 